\title{
Cross cultural validation of functional autonomy measurement system (SMAF) into Arabic geriatric rehab-culture
}

\author{
Albandary Alhadlaq ${ }^{1}$, Saleh Al Oraibi ${ }^{2}$, Fayz S. Al-Shahry ${ }^{3}$, Areej Al-Hawas, \\ Lamya Al-Qurashi ${ }^{4}$ and Mona Al-Otibiy ${ }^{4}$ \\ ${ }^{1}$ Occupational Therapy Student CAMS, KSAU-HS, Riyadh Saudi Arabia \\ ${ }^{2}$ Professor \\ ${ }^{3}$ Assistant Professor CAMS KSAU HS Consultant Rehabilitation, KSAU-HS, Riyadh Saudi Arabia \\ ${ }^{4}$ Occupational Therapy Students, KSAU-HS, Riyadh Saudi Arabia
}

\begin{abstract}
The Functional Autonomy Measurement System (FAMS) measures functional ability in Five domain: mobility, activities of daily living, instrumental activities of daily living, mental function and communication. FAMS however was validated into many languages such are English, Spanish, Japanese and Dutch, but it was not validated into Arabic. So, it may not suit Arabian cultures and society. Thus, the validation of FAMS into Arabic is vital. The aim therefore was to validate FAMS into Arabic culture. This is a prospective cross-sectional design. The study was conducted in Riyadh at King Abdul-Aziz Medical city (KAMC), in King Fahad Hospital (KFH) /in rehabilitation department. The FAMS was translated from original English version into Arabic. Translated Arabic version was distributed to 30 health professionals who work in rehabilitation department to check it for contents and accordingly FAMS was modified. Then, the final modified version of Arabic FAMS was distributed to 30 Saudis elderly who are 60 years old and above to test the question applicability and clarity. The results showed a measure of the internal consistency of our study by using Cronbach's alpha. The optimal value of this test is 0.7 and above. So, we found the value of our study was more than 0.7. The value was 0.9 for the 5 domains (ADL, Mobility, Communication, Mental function, IADL) which means it reliable for Arabic patients in Arabic cultures. The result revealed a new Arabic version of important assessment tool in the field of rehabilitation for the first time ever. The internal consistency of the FAMS assessment tool is in line with other previous similar validation research globally. Conclusion and clinical implications: The new translated Arabic version of FAMS was produced with Arabic cultural modifications. Further studies are needed to test this important assessment tools with larger population of Arab patients.
\end{abstract}

KEY WORDS: SOCIAL FUNCTIONING, FUNCTIONAL AUTONOMY, INSTRUMENTAL ACTIVITIES, OLDER PEOPLE, VALIDITY, ARABIC CULTURE

\section{ARTICLE INFORMATION:}

Corresponding Authors: shahryf@hotmail.com Received $12^{\text {th }}$ Oct, 2018

Accepted after revision $19^{\text {th }}$ Dec, 2018

BBRC Print ISSN: 0974-6455

Online ISSN: 2321-4007 CODEN: USA BBRCBA Thomson Reuters ISI ESC / Clarivate Analytics USA

Mono of Clarivate Analytics and Crossref Indexed Journal Mono of CR

NAAS Journal Score 2018: 4.31 SJIF 2017: 4.196

( $)$ A Society of Science and Nature Publication, Bhopal India 2018. All rights reserved.

Online Contents Available at: http//www.bbrc.in/

DOI: $10.21786 / \mathrm{bbrc} / 11.4 / 3$ 


\section{INTRODUCTION}

The Functional Autonomy Measurement System (FAMS) is a tool which developed in 1984 by a team from the Community Health Department at Hôtel-Dieu in Lévis to measure the demands and needs of the elderly handicapped (Hébert, Guilbault, Desrosiers, \&t Dubuc, 2001; Hébert, Carrier, \&t Bilodeau, 1988). SMAF quantifies the functional ability on 29-items scale which developed by World Health Organization's classification of impairments, handicaps and disabilities (Hébert, Robichaud, Roy, Bravo, \& Voyer, 2001). It measures functional ability in 5 sectors: mobility [6 items], activities of daily living (ADL) [7 items], instrumental activities of daily living (IADL) [8 items], mental functions [5 items] and communication [3 items] (Hébert, et al, 2001). These items were standardized using four-level measurement scale. Level 0: autonomous, Level 1: needs supervision or stimulation, Level 2: needs help, and Level 3: dependent (Hébert, et al 2001; Hébert et al, 1988; Hébert, et al, 2001). According to the occupational therapy practice framework: Doman \&t process, activities of daily living (ADLs) are activities that are specialized toward taking care of one's own body. Which are bathing, showering, toileting and toilet hygiene, dressing, swallowing/ eating, feeding, functional mobility, personal device care, personal hygiene and grooming, and sexual activity (Amini, D. A., Kannenberg, K., Bodison, S., Chang, P., Colaianni, D., Goodrich, B., \&t Lieberman, D., 2014). Not all the ADLs covered in the SMAF. The seven items included in SMAF are eating, washing, dressing, grooming, urinary continence, facial continence, and toileting (Hébert, Guilbault et al 2001).

Instrumental activities of daily living (IADLs) as in occupational therapy practice framework are "activities to support daily life within the home and community" (Amini et al, 2014) Care of others, care of pets, child rearing, communication management, driving and community mobility, financial management, health management and maintenance, home establishment and management, meal preparation and cleanup, religious and spiritual activities and expression, safety and emergency maintenance, and shopping are all considered IADLs" (Amini et al, 2014)

IADLs in the SMAF are meal preparation and cleanup, financial management, shopping, health management and maintenance, driving and community mobility, home establishment and maintenance (cleaning the house, and doing the laundry), and communication (Hébert, et al, 2001).

Disability is any restriction or lack (resulting from an impairment) of ability to perform an activity in the manner or within the range considered normal for a human being (World Health Organization,1980) World
Health Organization classified the disability into 9 categories (World Health Organization,1980). The first one is behavior disabilities which mention to a person's awareness of himself, others, their roles and occupations, places, and time (World Health Organization,1980). The second one is communication disabilities that refer to person's ability to communicate with other such as disability in speaking, listening, seeing, and writing (World Health Organization,1980). The third is personal care disabilities which mean the person's ability to take care of himself, his personal hygiene, dressing, feeding, and getting to bed (World Health Organization,1980). The fourth is locomotor disabilities which are disability in the walking, climbing stairs, running, transfer, transport, and lifting (World Health Organization,1980). The fifth is body disposition disabilities that mean the person's ability to carry out his own activities such as preparing food, cocking, serving food, reaching, and kneeling (World Health Organization,1980). The sixth is dexterity disabilities that refer to skill body movement such as modify the environment, moving and handling objects, fine motor control, and body control (World Health Organization,1980).

The seventh is situational disabilities that are disability in dependence, endurance, and disability in tolerance in the temperature, noise, and work stress (World Health Organization,1980). The eighth is particular skill disabilities that is disability in behavior such as intelligence, motivation, perception, learning, orientation, and concentration, and disability in achievement the tasks such as problem solving, adaptability, and accuracy (World Health Organization,1980). The last one is other activity restrictions; this section has been developed, in order to develop some of the categories that were not mentioned in the previous classifications (World Health Organization, 1980).

FAMS was validated into many languges such as English, Spanish, Japanese and Dutch, but it was not validated into Arabic. So, it may not suit our cultures and society (Desrosiers et al., 1995). Thus, the validation of FAMS into Arabic is vital (Desrosiers et al, 1995). It would help occupational therapists who work with people with disabilities and elderly who live in Arab counteries and speak Arabic languges in evaluating the areas of disability in them (Desrosiers et al, 1995).

Validation and realibility are independent on each other. A measurement maybe valid but not reliable, or reliable but not valid. Relibility is the reapition of findings (Kimberlin, \&t Winterstein, (2008). Validity of a test is that it measure what it is supposed measures (Kimberlin et al, 2008). We conducted this study to valiate SMAF culturally into Arabic culture. We choose prospective cross-sectional design to insure the willing of the participants. 


\section{Literature Review}

In 2009 Yount and Sibai found that By 2045-2050, the researchers expected that most (20 of 23) Arab populations are have at least 10 percent of population aged 60 and older. Hence, the Arabic country which have a largest number of elderly presently lived in it is Egypt (Yount \&t Sibai, 2009). The epidemiological research in Arab countries has been focused on non-communicable disorders and mostly on those of the circulatory system (Yount et al, 2009). The differences in Physical dependence with elderly are noted through out Arab countries with a high prevealance of ADL, IADL difficulties (Yount et al, 2009). The highest rates of limitations in ADL were shown in Tunisia, Egypt, Jordan and Lebanon (those reported between 25 and 38 percent) these countries followed by the UAE and Saudi Arabia which have between 17-19 percent (Yount et al, 2009). The limitations in ADL and IADL due to disability among women more than among men. However, there is lacking of measurement tools to assess functional limitations resulting In over-reporting of disabilities by the persons with disability (Yount et al, 2009). Based on that the women have shown higher difficulties in performing physicals tasks than men in Egypt, Tunisia, Jordan and Lebanon, but Egypt was reported as highest rates of restriction in performing physical tasks (PT) by 71 percent in men and 88 percent in women (Yount et al, 2009). Yount et al opined that capability to perform physical tasks (PT) is the most commonly used measurement to evaluate disability among elderly (Yount et al, 2009). "This measure is presumably independent of one's physical and social environment (e.g., cultural and gender roles), which would increase its validity and reproducibility and thereby make it preferable to measures of ADL and IADL disability" (Yount et al, 2009)

In two Canadian's studies used the SMAF as a measure using same study designs. Both studies used qusiexperimental design with elderly group patients aged 75 years. The first study included 151 elderlies from the geriatric day hospital and the second study included 1,501 persons identified at risk of functional decline (Tousignant, et al 2003; Hébert, et al 2009).

In another study using FAMS, they find that this tool was important tool to reduce elderly functional decline by identifying functional limitation at early stage, and Similarly Hébert Brayne, and Spiegelhalter used SMAF tool to measure functional movement, this helped identify risk factors of dependency and this helped to reduced the period of dependency in elderly group (Hébert, R., 1997; Hébert, R., Brayne, C., Etamp; Spiegelhalter, D, 1999).

Other functional studies carried out with elderly agreed that SMAF is very important tool and instrument synthesizes and systematizes the various scales proposed to measure the functioning of the elderly or disabled
(Mercier, et al, 2001; Pinsonnault, et al, 2003; Wales, et al, 2016). In All previous studies, they recruited similar age groups of fifty-five to seventy fife years old. All these studies were helped to evaluate the needs of individuals (elderly) by measuring the disabilities and the handicaps with which they are afflicted. These studies indicate that the FAMS is vital tool to measure the functional movement and independency in elderly groups as well as in people with disabilities. These very important in occupational therapy practice, make it worth studying it and translated and validated for people from other cultures rather than only people from western culture.

Additionally, another study aimed to apply the ISOSMAF classification to funding long-term care facilities in one area of the Province of Quebec and to compare the results of this new funding methodology to the formal methodology (Desrosiers, et al, 2004).

FAMS was validated into many languges such are English, Spanish, Japanese and Dutch, but it was not validated into Arabic. So, it may not suit our cultures and society (Desrosiers et al 1995). Thus, the validation of SMAF into Arabic is vital. The aim of this study is to valiate SMAF into Arabic culture. It would help occupational therapists who work with people with disabilities and elderly who live in Arab counteries and speak Arabic languges in evaluating the areas of disability in the Arabic elderly (Desrosiers et al, 1995). In the future, when there is an Arabic version, the method of evaluating elderly will be easy for the specialist and for patients. Also on the specialists' side it will be comfortable and easy for them because they will not make much effort to explain the point to patients, and it will save a lot of their time and effort (Desrosiers et al, 1995).

\section{METHODS}

The study was about cultural validation of Functional Autonomy Measurement System (FAMS) into Arabic culture. The study was conducted in Riyadh at King Abdulaziz Medical city (KAMC), in King Fahad Hospital (KFH) specifically in rehabilitation department. The capacity of beds in KAMC is 1501 beds. In 2003, the rehabilitation unite was only for neurological rehabilitation. The neurological rehabilitation unite expanded to be a rehabilitation department at 2004. Now, the rehabilitation department involve occupational and physiotherapy unites, In vitro fertilization (IVF), OB, medical imaging, laboratory, pharmacy, and continues renovation of patients' wards. (Ngha.med.sa. 2018). The Arabic version of FAMS was administered among 30 health providers in rehabilitation team including occupational therapists, physical therapists, physicans, nurses and 30 elderley patients 60 years and over after following the inclusion and exclusion criteria. The inclosion cri- 


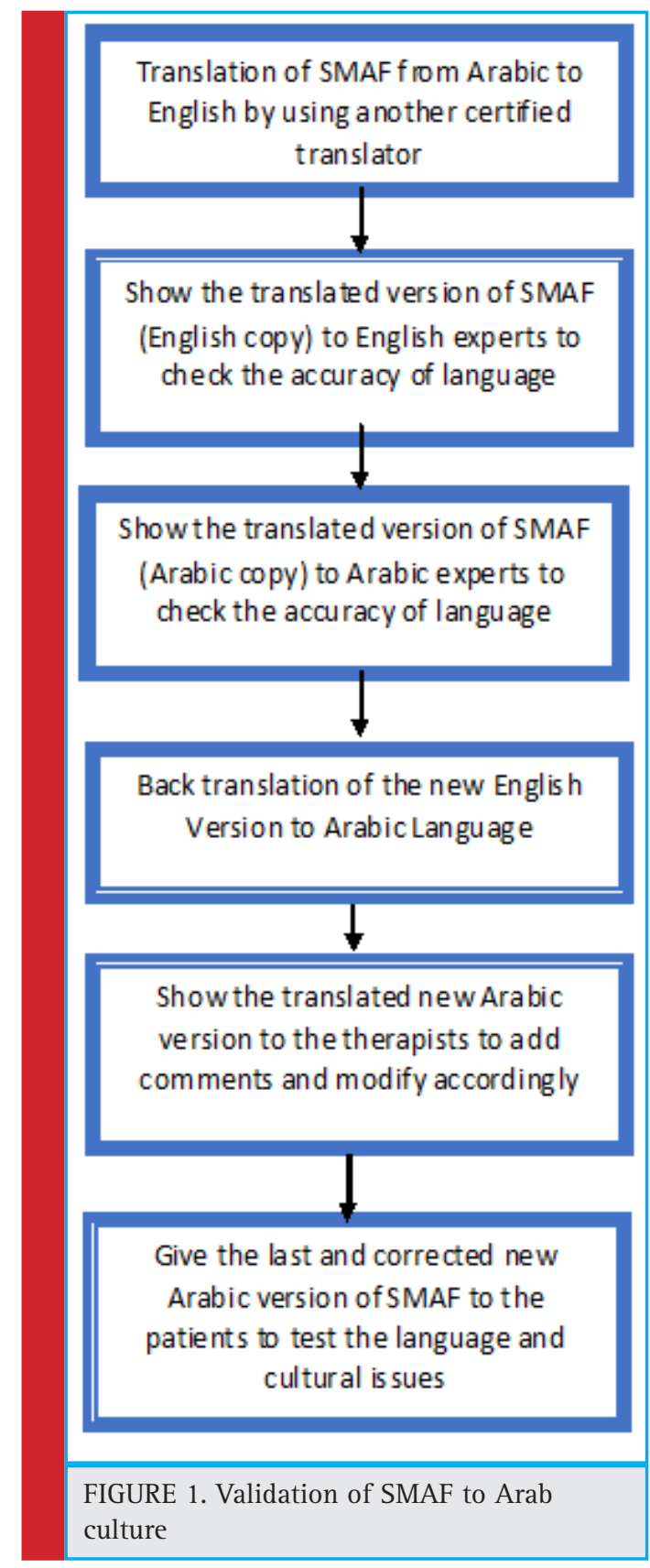

teria of this stude was the elderly should be 60 yearold and above, assess both genders and for those who have loss or limited of function. Howevere, participants who were below 60 year-old and anyone who have cognitive impairment were excloded from this study. The design for this study was prospective cross sectional. The sample size of this study was determined by the previous validation process in previous studies as listed in the reference list, (Beaton et al, 2000, Elboim-Gabyzon, et al 2015).

So, the estimated sample size for health providers who work in rehabilitation department in KAMC were
30 but we found only 19 health profissionals in rehabilitation team who are Arabic native speaker and for Saudi elderly clients over 60 years the sample size were 30 also. There is no randomization needed for this study. Purposeful sampling was used which means to select people who are willing to participate and available. The steps involved in the validation of SMAF to Arabic culture is given in Figure 1 and detailed as below.

\section{Stage I \& II: Initial Translation}

The first and second stage in adaptation were the forward translation. Two forward translations were made by two different certified translators. One certified translator was translated from English language into Arabic language, and then second translator was translated the tool from the new Arabic version into English language.

\section{Stage III \& IV: Synthesis of The Translations}

The third stage was to compare between the old English and the new English version to find any discrepancies and modify them. The fourth stage was to give the new Arabic version to Arabic language expert to check it for errors.

\section{Stage V: Back Translation}

The fifth stage was to translate the new English into Arabic language; This is a process of validity checking to make sure that the translated version is reflecting the same item content as the original versions.

\section{Stage VI: Expert Committee}

The sixth stage was to consult therapists about the new Arabic version and to receive their comments on it without using survey. Based on the comments from expert committee, modification was done on the Arabic version of FAMS.

\section{Stage VII: Test of the Pre-Final Version}

The final stage of adaptation process was the pretest. This field test of the new questionnaire seeks to use the pre-final version in subjects. Ideally, 30 persons were tested.

Accordingly, the final Arabic version of FAMS was edited and finalized and released to be used in upcoming studies.

\section{Ethical consideration and data management/ statistical plan:}

Ethical consideration:

Approval from IRB (King Abdullah Medical Research Center) was sought. An informed consent was completed prior to data collection. The researchers were safeguard the confidentiality of participants of the study. Personal data was stored on a computer with accessibility only to 
the researchers. Subject data was coded and names were not used in any of the documents related to this study.

Data management/ statistical plan:

Data was analyzed using SPSS statistical software, version 22. Descriptive statistics of means was used. Response frequencies and means or medians for the survey items were determined and displayed in tabular formats. After we completed the pilot study with 30 patients, the reliability of the new questionnaires items was tested using Cronbach's alpha.

\section{RESULTS}

The first stage was the distribution of the Arabic version of FAMS to nineteen native Arabic speakers both female and male health professionals who work in rehabilitation team to make sure that it is clear and valid for Arabic culture. After two weeks, we received the distributed FAMS. Following analysis of the data, twelve of them were satisfied and happy with the objective and identify that the objective of Arabic version is the same as the objective of original version. However, some of the participants suggested that for cultural purpose this tool needs to be completed by face to face interview instead of filling the form subjectively. The second step, after taking the opinions of experts into consideration and making modifications for the tables arrangement and sentence structure, we distributed the Arabic FAMS to thirty female and male Saudi elderly. The age group of the validation of FAMS differ from country to another, in Arabic culture elderly stage starts at sixty which is the retirement age in Arab countries. The mean of elderly participants age was 71.6 as seen in table 1 .

The participants in this research were representative for Arabic culture. They have different level of education; Master degree, Bachelor degree, high school, middle school, elementary school, and illiterate. Those participants differ in health status, some of them were in good health, however; others have chronic condition such as Diabetes, Irritable Bowel Syndrome, Hypertension, Osteoporosis, and Rheumatoid Arthritis and sever health conditions such as Hemodialysis, Breast Cancer, and heart disease. The female participants were twentyone and male participants were nine as seen in table 2 .

\begin{tabular}{|l|l|l|}
\hline \multicolumn{2}{|l|}{ Table 1. mean of elderly age } \\
\hline Statistics & & \\
\hline age & & \\
\hline $\mathrm{N}$ & Valid & 30 \\
\hline & Missing & 0 \\
\hline Mean & & 71.6667 \\
\hline
\end{tabular}

The result of distributing the FAMS to elderly in Arab culture was clear, simple, and easily understood for the participants. They satisfyingly answered all the questions of the Arabic version of FAMS. As a result, the Arabic version of FAMS is valid to be used with elderly in all Arab countries.

We used Cronbach's Alpha to measure the validity of the tool. The value of activity of daily living (ADL) was 0.914 . And the value of mobility was 0.914 . Also, the value of communication was 0.918 . The value of mental function was 0.917 . The value of instrumental activities of daily living (IADL) was 0.913. The optimal value of this test is 0.7 and above. The result that we found for all items in SMAF was 0.9 as seen in table 3.

\section{DISCUSSION}

The suitability of the content of FAMS for elderly people was reliable and valid and widely used in many countries. however the application of this scale in other nonEnglish speaking made the outcomes nonspecific and weary. In the Arab countries a notable boundaries were addressed by patients and families during the application of the FAMS in English version. the variation in the language interpretation and diversity in the meaning between Arabic and English was a real barrier. therefore this study was of extreme importance and the optimization of interpretation of the FAMS was the real challenge.

In this study, we validate the Arabic version of the functional Autonomy measurement system for the result, we have carried this study through two stages. In stage one, we distributed the Arabic version of FAMS to nineteen Arabic health professionals in rehab rehabilitation team. They were satisfied about it but they have some comments regarding the sentence structure. Based on their comments we modified the Arabic version to be

\begin{tabular}{|c|l|l|l|l|}
\hline \multicolumn{5}{|c|}{ Table 2. number of male and female who are participate in research. } \\
\hline \multicolumn{6}{|c|}{} & Frequency & Percent & Valid Percent & Cumulative Percent \\
\hline \multirow{2}{*}{$\begin{array}{c}\text { malid } \\
\text { female } \\
\text { Total }\end{array}$} & 9 & 30.0 & 30.0 & 30.0 \\
\cline { 2 - 6 } & 21 & 70.0 & 70.0 & 100.0 \\
\cline { 2 - 6 } & 30 & 100.0 & 100.0 & \\
\hline
\end{tabular}




\begin{tabular}{|c|c|c|c|c|c|}
\hline \multicolumn{6}{|c|}{ Item-Total Statistics } \\
\hline & $\begin{array}{l}\text { Scale Mean } \\
\text { if Item } \\
\text { Deleted }\end{array}$ & $\begin{array}{l}\text { Scale Variance } \\
\text { if Item Deleted }\end{array}$ & $\begin{array}{l}\text { Corrected Item- } \\
\text { Total Correlation }\end{array}$ & $\begin{array}{l}\text { Squared } \\
\text { Multiple } \\
\text { Correlation }\end{array}$ & $\begin{array}{l}\text { Cronbach's } \\
\text { Alpha if Item } \\
\text { Deleted }\end{array}$ \\
\hline activities_of_daily_living_eating & 93.6667 & 929.333 & .699 & . & .915 \\
\hline activities_of_daily_living_bathing & 93.6000 & 916.938 & .835 & . & .914 \\
\hline activities_of_daily_living_dressing & 93.6667 & 922.368 & .851 & . & .914 \\
\hline activities_of_daily_living_grooming & 93.7000 & 916.631 & .886 & . & .913 \\
\hline $\begin{array}{l}\text { activities_of_daily_living_urinary_ } \\
\text { function }\end{array}$ & 93.9333 & 935.237 & .767 & & .915 \\
\hline $\begin{array}{l}\text { activities_of_daily_living_bowel_ } \\
\text { function }\end{array}$ & 94.1000 & 954.231 & .631 & & .917 \\
\hline activities_of_daily_living_toiletting & 93.9000 & 941.610 & .604 & & .916 \\
\hline Mobility_TRANSFERS & 93.8333 & 934.144 & .756 & & .915 \\
\hline Mobility_WALKING_INSIDE & 93.6667 & 927.540 & .678 & & .915 \\
\hline $\begin{array}{l}\text { Mobility_PROPELLING_A_ } \\
\text { WHEELCHAIR_INSIDE }\end{array}$ & 93.9000 & 931.059 & .760 & . & .915 \\
\hline Mobility_NEGOTIATING_STAIRS & 92.9667 & 900.930 & .810 & . & .913 \\
\hline $\begin{array}{l}\text { Mobiliy_MOVING_AROUND_ } \\
\text { OUTSIDE }\end{array}$ & 93.2333 & 901.151 & .760 & . & .913 \\
\hline communication_vision & 93.8667 & 962.051 & .578 & . & .918 \\
\hline comunication_hearing & 94.1333 & 966.602 & .603 & . & .918 \\
\hline communication_speaking & 94.2000 & 969.407 & .569 & . & .919 \\
\hline mental_function_memory & 93.8667 & 957.844 & .687 & . & .917 \\
\hline mental_function_orientation & 94.0667 & 952.685 & .808 & . & .917 \\
\hline mental_function_COMPREHENSION & 94.1333 & 962.740 & .733 & & .918 \\
\hline mental_function_JUDGMENT & 93.9000 & 941.128 & .749 & & .916 \\
\hline mental_function_BEHAVIOUR & 94.0333 & 968.723 & .553 & & .919 \\
\hline $\begin{array}{l}\text { INSTRUMENTAL_ACTIVITIES_OF_ } \\
\text { DAILY_LIVING_HOUSEKEEPING }\end{array}$ & 93.0000 & 898.897 & .812 & & .913 \\
\hline $\begin{array}{l}\text { INSTRUMENTAL_ACTIVITIES_ } \\
\text { OF_DAILY_LIVING_MEAL__ } \\
\text { PREPARATION }\end{array}$ & 92.6000 & 902.041 & .755 & & .913 \\
\hline $\begin{array}{l}\text { INSTRUMENTAL_ACTIVITIES_OF_ } \\
\text { DAILY_LIVING_SHOPPING }\end{array}$ & 93.0333 & 894.378 & .829 & & .912 \\
\hline $\begin{array}{l}\text { INSTRUMENTAL_ACTIVITIES_OF_ } \\
\text { DAILY_LIVING_LAUNDRY }\end{array}$ & 92.7333 & 894.616 & .769 & & .913 \\
\hline $\begin{array}{l}\text { INSTRUMENTAL_ACTIVITIES_OF_ } \\
\text { DAILY_LIVING_TELEPHONE }\end{array}$ & 93.1667 & 912.833 & .835 & & .913 \\
\hline $\begin{array}{l}\text { INSTRUMENTAL_ACTIVITIES_OF_- } \\
\text { DAILY_LIVING_TRANSPORTATION }\end{array}$ & 93.1667 & 906.695 & .894 & . & .913 \\
\hline $\begin{array}{l}\text { INSTRUMENTAL_ACTIVITIES_OF_ } \\
\text { DAILY_LIVING_MEDICATION_USE }\end{array}$ & 93.2333 & 906.875 & .805 & . & .913 \\
\hline $\begin{array}{l}\text { INSTRUMENTAL_ACTIVITIES_OF_ } \\
\text { DAILY_LIVING_BUDGETING }\end{array}$ & 93.0667 & 898.133 & .803 & & .913 \\
\hline
\end{tabular}


more suitable Setubal and understandable for the Arabic speakers. The second stage, we distributed the modified Arabic version to 30 individuals from a representative elderly group. They were able to understand and answer all the questions with no difficulty and help.

This study considered to be the first study that validate FAMS to Arabic culture, which is one of the strength of this cross-sectional study. Another strength of this study, is that by now this version of FAMS is available to be used by all Arabic countries with different dialects. However, this study have some weakness. Although, the validation of FAMS into Arabic version has been completed, the sample size was small. Despite that we try to make it representative for older people living in Saudi Arabia in term of social-economic status, ethnicity, level of education, age, and health status. Thus, future research is needed to increase the sample size and better sampling technique in order to obtain valid information and to recheck our validity. The internal consistency for the study is 0.9 which consider a high consistency. In a study carried out by Desrosiers, et al., (1995) they used test re-test to measure the intraclass correlation reliability. While, in our study we used the Cronbach's alpha to measure the reliability, despite this the finding from previous study were similar to the present study (Desrosiers et al, 1995). In terms of ADL our present study was in agreement with Desrosiers, et al (1995) study. For the mobility part, present study was also in line with both Desrosiers et al. (1995) study and Desrosiers et al. (2004) study (Desrosiers et al, 1995; Desrosiers, et al, 2004).

However, for communication part, our study was in line with Desrosiers, et al. (1995); but was not in agreement with Desrosiers, et al (2004). The possible explanation could be because the 2004 study internal consistency for this part was different from our study which was range from 0.3 to 0.4 the same as the mental function. For IADL, our study In line with Desrosiers et al. (1995) study and Desrosiers et al. (2004) study (Desrosiers et al, 2004). By using Cronbach's alpha, the reliability and validity of the Arabic FAMS was measured. The internal consistency is used to measure the reliability. Therefore, we found that the Arabic version of FAMS is valid to be used in Arabic culture. However, further study to implement SMAF as measurement tools in Arab culture elderly will strengthen the tools and increase its reliability.

\section{CONCLUSION}

This research revealed that it is possible to validate western based rehabilitation tool into Arabic culture in order to use reliable measure. The new Arabic SMAF version is valid and reliable measure and culturally adapted tool to test ability of elderly people in Saudi Arabia and widely in Arab population. For the first time ever we introduced rehabilitation specialists with new tool appropriate for Arab culture and resources.

\section{REFERENCES}

Amini, D. A., Kannenberg, K., Bodison, S., Chang, P., Colaianni, D., Goodrich, B., \&t Lieberman, D. (2014). Occupational therapy practice framework: Domain \& process 3rd edition. American Journal of Occupational Therapy, 68, S1-S48.

Beaton, D. E., Bombardier, C., Guillemin, F., Etamp; Ferraz, M. B. (2000). Guidelines for the process of cross-cultural adaptation of self-report measures. Spine, 25(24), 3186-3191.

DESROSIERS, J., BRAVO, G., HÉBERT, R., Etamp; DUBUC, N. (1995). Reliability of the revised functional autonomy measurement system (SMAF) for epidemiological research. Age and ageing, 24(5), 402-406.

Desrosiers, J., Noreau, L., Robichaud, L., Fougeyrollas, P., Rochette, A., Etamp; Viscogliosi, C. (2004). Validity of the assessment of life habits in older adults. Journal of Rehabilitation Medicine, 36(4), 177-182.

Elboim-Gabyzon, M., Agmon, M., Azaiza, F., Ctamp; Laufer, Y. (2015). Translation and validation of the Arab version of the Late-Life Function and Disability Instrument: a cross sectional study. BMC geriatrics, 15(1), 51.

Ferraz, M. B. (1997). Cross cultural adaptation of questionnaires: what is it and when should it be performed? The Journal of rheumatology, 24(11), 2066.

Guillemin, F. (1995). Cross-cultural adaptation and validation of health status measures. Scandinavian journal of rheumatology, 24(2), 61-63.

Hébert, R., Carrier, R., \&t Bilodeau, A. (1988). The Functional Autonomy Measurement System (SMAF): description and validation of an instrument for the measurement of handicaps. Age and ageing, 17(5), 293-302.

Hébert, R. (1997). Functional decline in old age. Canadian Medical Association Journal, 157(8), 1037-1045

Hébert, R., Brayne, C., Ctamp; Spiegelhalter, D. (1999). Factors associated with functional decline and improvement in a very elderly community-dwelling population. American Journal of Epidemiology, 150(5), 501-510.

Hébert, R., Guilbault, J., Desrosiers, J., \&t Dubuc, N. (2001). The functional autonomy measurement system (SMAF): a clinicalbased instrument for measuring disabilities and handicaps in older people. Geriatrics Today, 4, 141-158.

Hébert, R., Robichaud, L., Roy, P. M., Bravo, G., \&t Voyer, L. (2001). Efficacy of a nurse-led multidimensional preventive programme for older people at risk of functional decline. A randomized controlled trial. Age and Ageing, 30(2), 147153.

Hébert, R., Durand, P. J., Dubuc, N., Ctamp; Tourigny, A. (2003). PRISMA: a new model of integrated service delivery for the frail older people in Canada. International journal of integrated care, $3(1)$ 
Hébert, R., Raîche, M., Dubois, M. F., Gueye, N. D. R., Dubuc, N., Tousignant, M., Etamp; PRISMA Group. (2009). Impact of PRISMA, a coordination-type integrated service delivery system for frail older people in Quebec (Canada): A quasi-experimental study. Journals of Gerontology Series B: Psychological Sciences and Social Sciences, 65(1), 107-118.

Kimberlin, C. L., \&t Winterstein, A. G. (2008). Validity and reliability of measurement instruments used in research. American Journal of Health-System Pharmacy, 65(23), 22762284.

Mercier, L., Audet, T., Hébert, R., Rochette, A., \&tamp; Dubois, M. F. (2001). Impact of motor, cognitive, and perceptual disorders on ability to perform activities of daily living after stroke. Stroke, 32(11), 2602-2608.
Pinsonnault, E., Desrosiers, J., Dubuc, N., Kalfat, H., Colvez, A., Etamp; Delli-Colli, N. (2003). Functional autonomy measurement system: development of a social subscale. Archives of gerontology and geriatrics, 37(3), 223-233.

Riyadh. (2016). Retrieved from http://ngha.med.sa/English/ MedicalCities/AlRiyadh/Pages/default.aspx

Tousignant, M., Hébert, R., Dubuc, N., Simoneau, F., Etamp; Dieleman, L. (2003). Applicationnof a case-mix classification based on the functional autonomy of the residents for funding long-term care facilities. Age and ageing, 32(1), 60-66.

Tousignant, M., Hébert, R., Desrosiers, J., Ctamp; Hollander, M. J. (2003). Economic evaluation of a geriatric day hospital: costbenefit analysis based on functional autonomy changes. Age and Ageing, 32(1), 53-59. 